\title{
PRODUÇÃO DE BIODIESEL ETÍLICO DE ÓLEO DE SOJA REFINADO EM ESCALA PILOTO
}

\author{
A. M. ESCORSIM ${ }^{1}$, L. R. S. KANDA ${ }^{1}$, G. PANINI ${ }^{2}$, A. ZANDONÁ FILHO ${ }^{2}$, F. A. P. VOLL ${ }^{2}$, J. $^{2}$ \\ L. A. DAGOSTIN ${ }^{2}$, M. L. CORAZZA ${ }^{2}$ e L. P. RAMOS ${ }^{1}$ \\ ${ }^{1}$ Universidade Federal do Paraná, Departamento de Química \\ ${ }^{2}$ Universidade Federal do Paraná, Departamento de Engenharia Química \\ E-mail para contato: corazza@ufpr.br
}

\begin{abstract}
RESUMO - Devido ao crescente interesse no uso do biodiesel, é indispensável a realização de estudos em escala piloto utilizando etanol ao invés de metanol, devido a fatores ambientais, econômicos e de segurança. Assim, este trabalho objetivou produzir $1.000 \mathrm{~L} /$ dia de biodiesel etílico a partir de óleo de soja refinado e utilizando metilato de sódio como catalisador, conforme as recomendações do Instituto de Investigaciones en Catálisis y Petroquimica (INCAPE, Argentina). A reação foi realizada em duas etapas: na primeira, o tempo foi de 30 min e a razão molar etanol:óleo:catalisador foi de 2,55:1:0,1; na segunda, o tempo foi de $60 \mathrm{~min}$, com razão molar de 1,70:1:0,1. Após cada etapa de reação o sistema foi deixado em repouso para separação e remoção do glicerol. Os ésteres foram então purificados através de lavagens com água ácida e com água pura. Ao final, foram obtidos teores de ésteres acima de $96 \% \mathrm{~m} / \mathrm{m}$, demonstrando a viabilidade da produção de biodiesel etílico com boa qualidade nesta escala.
\end{abstract}

\section{INTRODUÇÃO}

O uso da biomassa é apontado como uma grande opção na procura por novas fontes de bioenergia. Dentre estas, destaca-se o biodiesel por ser renovável, biodegradável, não tóxico, livre de enxofre e aromáticos e com propriedades físico-químicas semelhantes ao diesel de petróleo (Demirbas, 2008; Ferreira, 2010).

O potencial do uso do biodiesel como fonte energética é um dos assuntos mais discutidos nos dias atuais em âmbito industrial e acadêmico, embora esse "velho" combustível já seja utilizado em um grande número de países mesmo enfrentando sérias dificuldades para competir com o diesel de petróleo, o que tem forçado alguns países a estabelecer programas de subsídio ou de uso obrigatório de misturas com diesel, como é o caso do Brasil (Dabdoub et al., 2009). Além disso, o aumento do consumo energético mundial pode levar ao esgotamento de fontes energéticas não renováveis derivadas de petróleo. Assim sendo, seja pela exaustão das reservas ou pelos efeitos negativos causados ao meio ambiente, a diversificação da matriz energética mundial por meio da busca por fontes renováveis de energia é imprescindível (Ramos, 2014).

Atualmente, o biodiesel é produzido e utilizado comercialmente em muitos países do mundo todo, seja puro ou misturado com o diesel, sendo que esta mistura é estável em qualquer proporção, de modo que os motores a diesel podem ser utilizados sem grandes adaptações. Tradicionalmente, são utilizados como matérias-primas para a produção de biodiesel, óleos 
vegetais como os de soja, palma, girassol, amendoim, colza e algodão, entre outros (Mittelbach e Remschmidt, 2005).

O processo de produção do biodiesel empregado mundialmente é baseado na transesterificação alcalina em meio homogêneo, geralmente utilizando como catalisadores alcóxidos ou hidróxidos de sódio ou potássio. A utilização de hidróxidos resulta em menores conversões em ésteres, uma vez que o catalisador é consumido em uma reação de saponificação, que ocorre devido à presença de água formada na reação do álcool com o hidróxido, ficando indisponível para realizar a reação de transesterificação. Com relação aos alcóxidos, a atividade do metilato de potássio é ligeiramente maior do que a do metilato de sódio, mas devido ao seu menor custo e maior disponibilidade, é dada preferência ao metilato de sódio, inclusive em reações de etanólise (Mendow et al., 2011a, b).

Os álcoois mais utilizados no processo de fabricação do biodiesel são o metanol e o etanol. O etanol é mais utilizado nos países onde há abundância de colheitas ricas em carboidratos, como é o caso do Brasil, onde o etanol é produzido pela fermentação do caldo extraído da cana-deaçúcar por leveduras. (ANP, 2014). Além disso, o biodiesel etílico apresenta vantagens com relação ao biodiesel metílico, como menor toxicidade, ponto de névoa, ponto de fluidez e emissão de dióxido de carbono, bem como maior rendimento em ésteres, pois partindo de $100 \mathrm{~g}$ de óleo, podem ser obtidos 105,2 g de biodiesel etílico ante 100,5 g de biodiesel metílico (Mendow et al., 2011b; Stamenkovic et al., 2011).

Por outro lado, a dificuldade de obtenção do etanol isento de água e as reações secundárias que ocorrem devido à presença desta no meio reacional, reduzindo o rendimento de formação dos ésteres, somada ao fato de que a maioria das unidades em escalas piloto ou industrial operam utilizando metanol, fica evidente que os parâmetros de processo para a produção do biodiesel etílico ainda devem ser otimizados (Brunschwig et al., 2012).

Neste contexto, o foco deste trabalho é realizar a síntese de biodiesel por etanólise em meio alcalino homogêneo de óleo de soja refinado comercial, utilizando uma unidade em escala piloto com capacidade de produção de $1.000 \mathrm{~L} /$ dia e determinando as condições operacionais ótimas e a melhor sequência das operações unitárias do processo.

\section{MATERIAL E MÉTODOS}

\subsection{Materiais}

O óleo de soja refinado comercial foi adquirido junto à empresa IMCOPA (Araucária, PR). O metóxido de sódio comercial foi gentilmente fornecido pela EVONIK (São Paulo, SP). Os demais reagentes, solventes e padrões empregados foram de grau analítico para análise (PA).

\subsection{Caracterização das matérias-primas e produtos gerados}

Para a determinação dos parâmetros físicos e químicos dos óleos vegetais comerciais utilizados como matéria prima, foram utilizados métodos padronizados para a determinação dos teores de ácidos graxos livres (AOCS Ca-5a-40), índice de saponificação (AOCS Cd 3-25), teor de cinzas (AOCS Ca 11-55), teor de sabão (AOCS Cc 17-79), índice de iodo (AOCS Cd 1-25), massa específica (EN ISO 3675), umidade e voláteis (IAL, 2004) e viscosidade (ASTM D6751). 


\subsection{Determinação das concentrações dos ésteres de acilgliceróis produzidos, glicerol livre, metanol e etanol residuais}

A quantificação de ésteres alquílicos de ácidos graxos provenientes das matérias-primas oleosas foi realizada utilizando-se cromatografia em fase gasosa (Thermo-Trace 1310) com injetor split/split-less (modo PTV), detector de ionização de chama (FID) e sistema de processamento de dados ChromQuest 5.0. Foi utilizada uma coluna Select Biodiesel para acilgliceróis (CP9080) com $30 \mathrm{~m} \times 0,25 \mathrm{~mm} \times 0,25 \mu \mathrm{m}$. A temperatura no detector foi de $420{ }^{\circ} \mathrm{C}$; no injetor, inicialmente a temperatura foi de $70{ }^{\circ} \mathrm{C}$ por $0,1 \mathrm{~min}$, em seguida a temperatura foi elevada para $100{ }^{\circ} \mathrm{C}$ com taxa de aquecimento de $5{ }^{\circ} \mathrm{C} / \mathrm{s}$ e tempo de espera de 2 minutos e para $410{ }^{\circ} \mathrm{C}$ com taxa de aquecimento de $10^{\circ} \mathrm{C} / \mathrm{s}$ e tempo de espera de 28 minutos; e, na coluna, a temperatura inicial foi de $90{ }^{\circ} \mathrm{C}$, a seguir a temperatura foi elevada para $150{ }^{\circ} \mathrm{C}$ com taxa de aquecimento de $4{ }^{\circ} \mathrm{C} / \mathrm{s}$ e tempo de espera de 0,5 minuto, para $190{ }^{\circ} \mathrm{C}$ com taxa de aquecimento de $7{ }^{\circ} \mathrm{C} / \mathrm{s}$ e tempo de espera de 0,5 minuto, para $220^{\circ} \mathrm{C}$ com taxa de aquecimento de $10{ }^{\circ} \mathrm{C} / \mathrm{s}$ e tempo de espera de 0,5 minuto e para $350{ }^{\circ} \mathrm{C}$ com taxa de aquecimento de $40{ }^{\circ} \mathrm{C} / \mathrm{s}$ e tempo de espera de 2 minutos. O volume de amostra injetada foi de 1,5 $\mu \mathrm{L}$ e os gases utilizados foram: ar sintético e hidrogênio em razão de 10:1 (v/v) e nitrogênio como gás de arraste $(0,8 \mathrm{~mL} / \mathrm{min})$ em modo split de 1:10. Para a quantificação dos ésteres foi utilizado padronização externa.

Para a quantificação de glicerol livre, metanol e etanol residuais foi utilizada cromatografia em fase líquida (Shimadzu LC10AD), sendo o equipamento provido de um amostrador automático SIL10A, um degaseificador de fase móvel modelo DGU14A, um forno de aquecimento de coluna modelo CTO10A e um detector de índice de refração RID10A. A análise foi realizada em coluna Aminex HPX-87H (Bio-Rad) a $65{ }^{\circ} \mathrm{C}$, precedida por uma pré-coluna Cátion-H e eluída com fase móvel $\mathrm{H}_{2} \mathrm{SO}_{4} 5 \mathrm{mmol}$. $\mathrm{L}^{-1}$ a uma vazão de $0,4 \mathrm{~mL} \cdot \mathrm{min}^{-1}$. A quantificação foi feita por padronização externa, sendo que para cada componente analisado foi construída uma curva de calibração. Os métodos cromatográficos de quantificação dos ésteres etílicos e metílicos dos ácidos graxos foram validados segundo a norma EN ISO/IEC 17025.

\subsection{Reação catalítica homogênea e purificação}

O processo de transesterificação ocorreu em uma unidade convencional de produção de ésteres - U200 (Figura 1), localizada no Núcleo de Pesquisas e Desenvolvimento de Energias Sustentáveis (NPDEAS - UFPR), sendo o aquecimento da unidade realizado por vapor saturado gerado em caldeira da marca WECO.

As reações de transesterificação foram realizadas conforme descrito por Mendow et al. (2011b), em um processo que consiste de duas etapas reacionais em que o catalisador utilizado é o metilato de sódio comercial (30\% em metanol) (Evonik Industries). Na primeira etapa reacional, o material graxo armazenado no tanque TQ 1 foi bombeado até o TQ 2 (misturador) e este foi bombeado para o TQ 3 (reator), onde foi aquecido a $55^{\circ} \mathrm{C}$ sob agitação constante. Neste intervalo de aquecimento do óleo, o metilato de sódio na proporção de $0,55 \%(\mathrm{~m} / \mathrm{m})(\mathrm{em}$ relação à massa de óleo) foi misturado com o etanol a uma razão molar álcool:óleo:catalisador de 2,55:1:0,09, levando em consideração a molaridade do metanol contido no metilato de sódio.

Após 30 minutos de reação, contados a partir da adição da mistura catalisador/etanol ao TQ 3, o sistema de agitação e o aquecimento foram interrompidos e o meio de reação foi transferido 
para o TQ 4 (evaporador) e então para o TQ 6 (decantador), onde permaneceu em repouso por até 3 horas para separação das fases (uma rica em glicerina e a outra rica em óleo e ésteres). Em seguida, a fase superior rica em óleo e ésteres foi transferida para o TQ 9 (ésteres parciais) e então para o TQ 3 (reator), onde foi aquecido a $55^{\circ} \mathrm{C}$ e a segunda etapa reacional foi iniciada.

Durante o intervalo no qual o óleo foi aquecido, novamente foi feito o preparo da mistura de catalisador com o etanol a $0,55 \%(\mathrm{~m} / \mathrm{m})$ em relação à massa inicial de óleo, mas na segunda etapa a razão molar etanol:óleo foi de 1,70:1, ressaltando que a molaridade de metanol contida no metilato de sódio também foi considerada.

Ao final do tempo de reação de 1 hora, iniciado a partir da adição da mistura catalisador/etanol, o sistema de agitação e o aquecimento foram interrompidos e o meio de reação foi bombeado para o TQ 4 (evaporador) e, em seguida, para o TQ 7 (decantador) onde foi deixado em repouso até a separação das fases glicerina/ésteres etílicos.

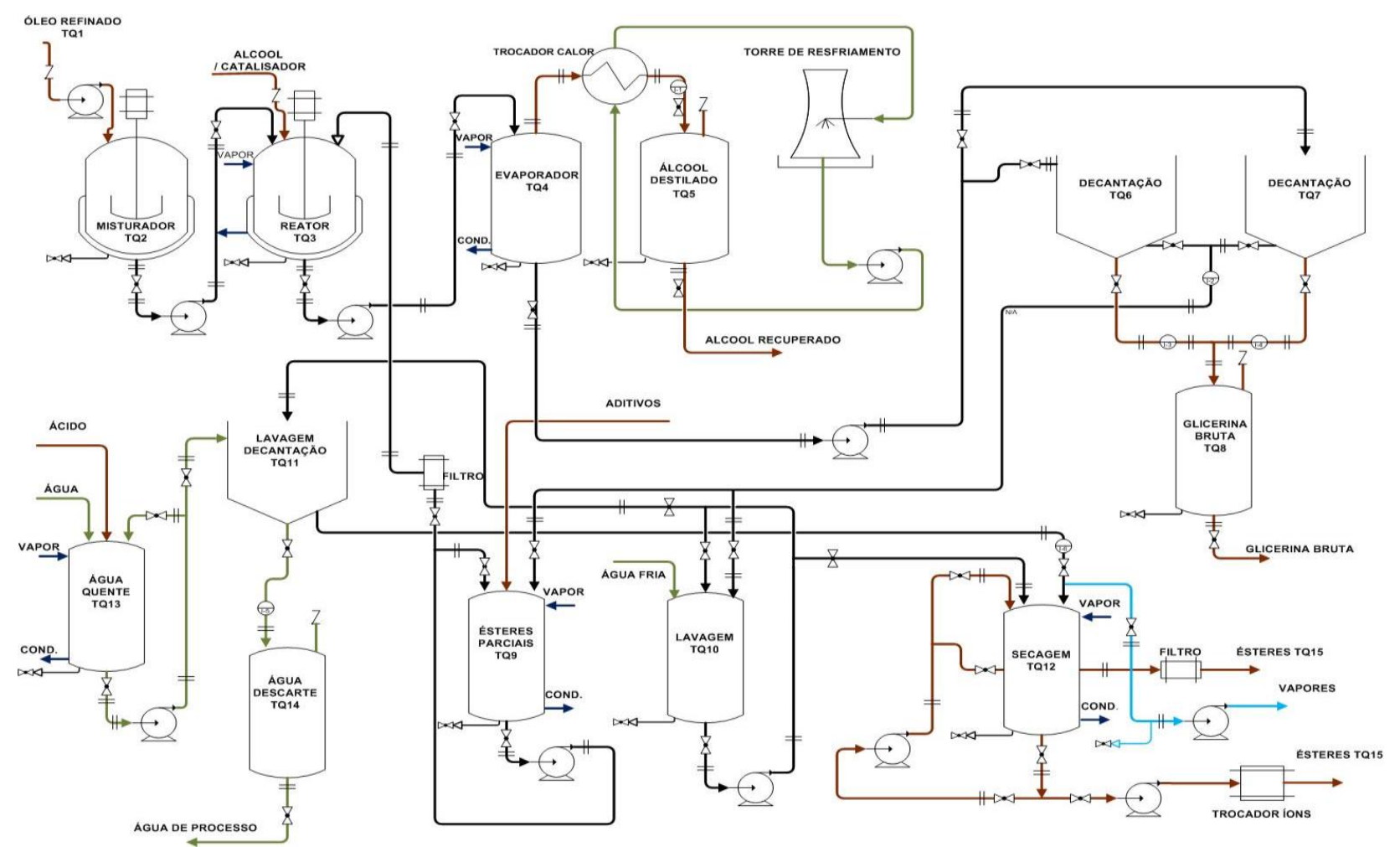

Figura 1 - Fluxograma do processo de produção - U200.

Após a separação de fases no TQ 7, a fase rica em glicerina foi transferida para o TQ 8 (glicerina bruta) e a fase rica em éster para o TQ 10 (lavagem), onde foi aquecida a $60{ }^{\circ} \mathrm{C}$ e, em seguida, a água previamente aquecida a $60{ }^{\circ} \mathrm{C}$ foi transferida do TQ 13 (água quente) para o TQ 10, em uma quantidade de $10 \%$ (v/v) do volume de ésteres por 3 vezes, sendo a primeira e a terceira lavagem somente com água e a segunda lavagem com água ácida $(5 \%(\mathrm{~m} / \mathrm{m})$ de ácido clorídrico P.A. em relação a massa de água). A lavagem foi feita com recirculação do conteúdo do 
tanque por 15 minutos para um melhor contato entre as espécies químicas presentes. Em seguida, o conteúdo do TQ 10 foi transferido para o TQ 11 (lavagem decantação) até separação de fases ésteres/água. Deste tanque, a fase rica em ésteres era transferida para o TQ10, conforme a necessidade da realização de outros procedimentos de lavagem e a fase água ácida/sabão foi transferida para o TQ 14 (água descarte).

Finalmente, os ésteres formados foram transferidos para o TQ 12 (secagem), onde foram aquecidos a $60{ }^{\circ} \mathrm{C}$, e a umidade foi retirada mediante aplicação de vácuo, com recirculação por 30 minutos, em seguida foi realizada a filtração dos ésteres, que foram encaminhados ao TQ 15 (ésteres totais) para armazenamento.

\subsection{Cálculo de rendimento da reação}

O rendimento mássico foi calculado a partir da massa inicial de óleo e do resultado mássico de ésteres totais ao final da melhor condição de operação obtida por Mendow et al. (2011b). Para o cálculo desse rendimento foi utilizada a Equação 1 sugerida por Kucek et al. (2007):

$$
Y_{E}=\frac{M_{F S L}-T_{E}}{M_{0}-F C} \times 100
$$

onde, $\mathrm{M}_{\mathrm{FSL}}$ : massa da fração superior após a lavagem, em $\mathrm{Kg} ; \mathrm{M}_{\mathrm{o}}$ : massa do óleo, em kg; $\mathrm{T}_{\mathrm{E}}$ : teor de ésteres, em \%; $\mathrm{Y}_{\mathrm{E}}$ : rendimento real de ésteres, em \%; FC: fator de conversão do óleo em ésteres (para rota etílica, 105,2\%).

\section{RESULTADOS}

\subsection{Caracterização das matérias-primas}

As propriedades físico-químicas do óleo de soja refinado comercial utilizado foram as seguintes: índice de acidez de 0,058 $\pm 0,001 \%$ em relação ao ácido oleico; índice de saponificação de $177,99 \pm 2,73 \mathrm{mg} \mathrm{KOH} . \mathrm{g}^{-1}$, que corresponde ao material graxo passível de transformação em monoésteres graxos e possibilitou a determinação da massa molar média (MM) de 945,64 $\pm 14,51$ g.mol ${ }^{-1}$; índice de iodo de $126,812 \pm 2,428 \mathrm{~g} \mathrm{I}_{2} .100 \mathrm{~g}^{-1}$, sendo este um parâmetro relacionado com a quantidade de ácidos graxos insaturados; massa específica a $15{ }^{\circ} \mathrm{C}$ de $0,923 \pm 0,001$ g.mL $\mathrm{mL}^{-1}$; viscosidade cinemática a $40{ }^{\circ} \mathrm{C}$ de $27,850 \pm 0,003 \mathrm{~mm}^{2} \cdot \mathrm{s}^{-1}$; umidade e voláteis de $0,004 \pm 0,001 \%$ $(\mathrm{m} / \mathrm{m})$ e teor de cinza não detectado, ou seja, não apresentou resíduos inorgânicos. Como observado, os índices de acidez, de iodo e de saponificação e a massa especifica encontram-se dentro dos limites estabelecidos pela Agência Nacional de Vigilância Sanitária (ANVISA), RDC no 270 de 22/09/2005 - Regulamento Técnico para Óleos Vegetais, Gorduras Vegetais e Creme Vegetal.

\subsection{Quantificação dos ésteres (m)etílicos produzidos, glicerol livre e metanol e etanol residuais}

A reação de transesterificação foi inicialmente proposta para diminuir a viscosidade dos óleos vegetais, a qual impede sua aplicação em motores a diesel (Alves et al., 2010). Neste estudo, a viscosidade foi reduzida aproximadamente seis vezes a inicial, ou seja, de $27,850 \pm 0,003 \mathrm{~mm}^{2} . \mathrm{s}^{-1}$ 
para 4,926 $\pm 0,001 \mathrm{~mm}^{2} \cdot \mathrm{s}^{-1}$. A massa específica também apresentou queda: de $0,923 \pm 0,001 \mathrm{mg} \cdot \mathrm{mL}^{-}$ ${ }^{1}$ de óleo de soja refinado para $0,883 \pm 0,001$ g.mL ${ }^{-1}$ do biodiesel.

O valor do índice de acidez do biodiesel foi de $0,117 \pm 0,001 \%$ em relação ao ácido oleico, ou seja, a acidez aumentou se comparada com a acidez da matéria-prima, fato que está relacionado à lavagem ácida dos ésteres. O valor do índice de iodo foi de $123,074 \pm 0,330 \mathrm{~g} \mathrm{I}_{2} .100 \mathrm{~g}^{-1}$ indicando que, apesar de ser menor do que o valor inicial, houve pouca degradabilidade do material. Os parâmetros de teor de acidez e de iodo são importantes para controle de qualidade dos ésteres, pois estão relacionadas com fatores de deterioração por termo-oxidação ou por ataque de radicais livres em suas insaturações, além de reflexos sobre sua inflamabilidade e abaixamento no ponto de névoa.

A legislação não define os limites máximos de teor de sabão no biodiesel, mas define o teor máximo de metais alcalinos e alcalino-terrosos, o que acaba sendo detectado pela presença de sabões. Na transesterificação de óleos vegetais, a água tem um papel negativo, principalmente a temperaturas mais elevadas, pois permite a hidrólise dos ésteres de ácidos graxos, formando ácidos graxos livres que são neutralizados pelo catalisador básico, desativando-o e formando sabão. Além disso, a presença de sabão pode aumentar a concentração de glicerina no biodiesel devido à formação de emulsões (Marçon, 2010). O teor de sabão no biodiesel produzido foi de 0,091 $\pm 0,001$ ppm.

Entre as impurezas da queima automotiva do biodiesel, as cinzas expressam os resíduos inorgânicos não combustíveis. Devido ao seu processo de fabricação, alguns metais podem estar presentes nas cinzas de biodiesel e o monitoramento quantitativo destas é de fundamental importância, pois teores de cinzas acima das especificações legais podem causar corrosão e entupimentos em motores, além de causar risco à saúde humana e ao meio ambiente. Neste estudo, não foi detectada a presença de cinzas ou de resíduos inorgânicos.

O teor de umidade e voláteis presente no biodiesel foi de $0,382 \pm 0,012 \%(\mathrm{~m} / \mathrm{m})$, o que ocorre devido à presença de água nos reagentes utilizados. Isto pode ser explicado pelo fato de que o etanol e o catalisador são higroscópicos.

O teor de glicerol livre presente no biodiesel foi de $0,0009 \pm 0,0001 \%(\mathrm{~m} / \mathrm{m})$, ficando abaixo do limite estabelecido pela legislação vigente $0,02 \%(\mathrm{~m} / \mathrm{m})$. Não foram detectados traços de metanol residual no biodiesel, indicando um consumo total deste no meio reacional. $\mathrm{O}$ teor de etanol residual no biodiesel foi de $0,0138 \pm 0,0016 \%(\mathrm{~m} / \mathrm{m})$, também inferior ao limite de $0,2 \%$ $(\mathrm{m} / \mathrm{m})$ que é estabelecido pela legislação vigente.

Os teores de ésteres totais e rendimentos mássicos obtidos a partir do processamento de óleo de soja refinado comercial por transesterificação alcalina variaram de $92,83 \%$ a $99,21 \%(\mathrm{~m} / \mathrm{m})$, com média de $96,06 \pm 3,42 \%(\mathrm{~m} / \mathrm{m})$, e rendimentos entre 85,31 a $91,18 \%(\mathrm{~m} / \mathrm{m})$, com média de $88,28 \pm 3,14 \%(\mathrm{~m} / \mathrm{m})$. Os teores de ésteres obtidos foram satisfatórios, apesar de ligeiramente abaixo do permitido pela legislação vigente, que é de 96,5\%. Já o baixo rendimento obtido está relacionado a perdas de ésteres na fase da glicerina bruta, pois a presença do etanol não retirado do processo aumenta a miscibilidade dos ésteres na fase rica em glicerina, e a perdas de ésteres nos processos de lavagem. A fase rica em glicerina representou de 15 a $20 \%$ (v/v) em relação aos ésteres produzidos, quando o esperado é em torno de $10 \%$ (v/v). 


\section{CONCLUSÕES}

A etapa da síntese foi concluída obtendo o rendimento mássico médio de $88,28 \pm 3,14 \%$ em biodiesel proveniente do óleo refinado comercial, com teores de ésteres totais médios de $96,06 \pm 3,42 \%$. Este processo pode ser aplicado em processos industriais tanto com metanol quanto com etanol. Estudos complementares poderão ser realizados focando o aumento no rendimento através de uma automatização e melhora no procedimento de separação (TQ 6 e TQ 7) da unidade U200. A estratégia de duas etapas de reação possibilitou um maior rendimento na conversão obtendo o biodiesel etílico com maiores teores de ésteres, o que satisfez as exigências de norma. O ponto de maior sustentabilidade do processo está na relação molar álcool:óleo que foi de 4,25:1, valor inferior ao utilizado nas rotas metílicas.

\section{REFERÊNCIAS}

ALVES, I. L.; MOZER, F.; MARQUES, F. C. Produção do biodiesel utilizando óleo de soja da cantina do IFES, Campus Cachoeiro do Itapemirim-ES. Inst. Fed. de Ed. Ciência e Tecnologia do Espírito Santo, 2010.

ANP - Agência Nacional do Petróleo, Gás Natural e Biocombustíveis. Disponível em: <http://www.anp.gov.br/biocombustiveis/biodiesel.asp>. Acesso em: 09/01/2014.

BRUNSCHWIG, C.; MOUSSAVOU, W.; BLIN, J. Use of bioethanol for biodiesel production. Prog. Energy Combust. Sci., v. 38, p. 283-301, 2012.

DABDOUB, M. J.; BRONZEL, J. L.; RAMPIN, M. A. Biodiesel: visão crítica do status atual e perspectivas na academia e na indústria. Quím. Nova, v.32, p.776-792, 2009.

DEMIRBAS, A. Importance of biomass energy sources for Turkey. J. Energy Policy. p. 834842, 2008.

FERREIRA, F. M. Equilíbrio de fases em altas pressões do ácido láurico e metanol em $\mathrm{CO}_{2}$. Dissertação de Mestrado - PPGEQ - UFPR, 2010.

KUCEK, K. T.; OLIVEIRA, M. A. F. C.; WILHELM, H. M.; RAMOS, L. P. Ethanolysis of refined soybean oil assisted by sodium and potassium hydroxides. J. Am. Oil Chem. Soc., v. 84, p. 385-392, 2007.

MARÇON, R. O. Pré-tratamento da glicerina bruta gerada na produção de biodiesel por transesterificação de óleos vegetais e gordura animal. UFTO. Palmas/TO, 2010.

MENDOW, G.; VEIZAGA, N. S.; QUERINI, C. A. Ethyl ester production by homogeneous alcaline transesterification: influence of the catalyst. Bioresour. Technol., v. 102, p. 6385-6391, 2011a.

MENDOW, G.; VEIZAGA, N. S.; SÁNCHEZ, B. S.; QUERINI, C. A. Biodiesel production by two-stage transesterification with ethanol. Bioresour. Technol., v. 102, p. 1040710413, 2011b.

MITTELBACH, M.; REMSCHMIDT, C. Biodiesel: the comprehensive handbook. $2^{\mathrm{a}} \mathrm{Ed}$, Vienna, Paperback, p. 330, 2005. 
RAMOS, L. P. A evolução nas tecnologias de produção de biodiesel. Disponível em: $<$ http://www.biodieselbr.com/colunistas/ramos/evolucao-tecnologias-producao-biodiesel-14-0114.htm>. Acessado em: 02/04/2014.

STAMENKOVIC, O. S.; VELICKOVIC, A. V.; VELJKOVIC, V. B. The production of biodiesel from vegetable oils by ethanolysis: Current state and perspectives. Fuel, v. 90, p. 31413155, 2011. 